\title{
DOI:10.26726/1812-7096-2020-12-141-148 \\ СИСТЕМА НАЛОГООБЛОЖЕНИЯ БАНКОВСКИХ ОРГАНИЗАЦИЙ: СОСТОЯНИЕ И ПУТИ ПОВЫШЕНИЯ ЭФФЕКТИВНОСТИ
}

\begin{abstract}
Аннотауия. Предмет исследования - анализ действующей системы налогообложения

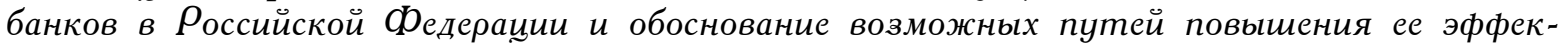
тивности. Методология. Методологической основой исследования послужили фундаментальные и прикладные работы российских и зарубежных специалистов в области налогообложения и администрирования банков. Исследование осуществлялось на основе применения таких общенаучных методов исследования, как научный поиск и обобщение, индукция и дедукиия, экономико-статистический анализ, комплексный и системный подходы. Результаты. Проанализированы особенности и дана оценка ключевым проблемам налогообложения банковского сектора экономики на современном этапе $\rho_{\text {оссийской }} \mathrm{dp}_{e-}$ дерации. Показана иелесообразность и предложен вариант дифференииации ставок налога на прибыль для банковских организаций по видам операций, услуг и сделок. Аргументирована целесообразность налогообложения спекулятивных операций, валютных и финансовых транзакиий по повышенной ставке налогом на прибыль, ито позволит компенсировать потери бюджета в связи с введением низкой ставки налога по кредитованию инновационной деятельности, наукоемких отраслей и реального сектора экономики. Выявлена необходимость устранения существующих противоречий в налоговом законодательстве, совершенствования системы ответственности банков с иелью минимизаций правонарушений с данного сегмента экономики. Область применения резудьтатов иссле-

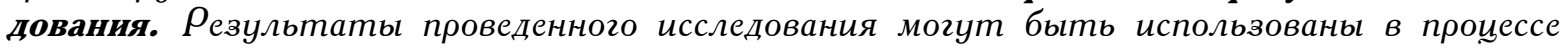
принятия нормативно-правовых актов, направленных на совершенствование законодательства в области налогообложения банковского сектора экономики. Выводы. Основным выводом проведенного исследовании является обоснование необходимости формирования налоговой тактики и стратегии в отношении банков - инвесторов, необходимости налоговой поддержки банковского кредитования приоритетных отраслей экономики на основе дифференциащии ставок налога на прибыль по видам банковской деятельности и оказываемым услугам.
\end{abstract}

Ключевые слова: банковские организации, система налогообложения, налог на прибыль, кредитование, налоговая ответственность, транзакиии, спеииальный налог.

\section{MUSAEVA KHAIBAT MAGOMEDTAGIROVNA}

Ph.D. in Economics, Associate Professor, Department of finance and credit Federal state educational institution of higher education «Dagestan State University»,Russian Federation, e-mail:khaybatuma@gmail.com

\section{THE SYSTEM OF TAXATION OF BANKING ORGANIZATIONS: STATUS AND WAYS TO IMPROVE EFFICIENCY}

Abstract. The subject of the study is the analysis of the current system of taxation of banks in the Russian Federation and the justification of possible ways to improve its efficiency. Methodology. The methodological basis of the research is based on the fundamental and applied works of Russian and foreign specialists in the field of taxation and bank administration. The research was carried out on the basis of such general scientific research methods as scientific search and generalization, induction and deduction, economic and statistical analysis, complex and systematic 
approaches. Results. The article analyzes the features and assesses the key problems of taxation of the banking sector of the economy at the present stage of the Russian Federation. The expediency of differentiation of income tax rates for banking organizations by types of operations, services and transactions is shown and proposed. The expediency of taxation of speculative transactions, currency and financial transactions at an increased rate of income tax is argued, which will compensate for budget losses due to the introduction of a low tax rate on lending to innovative activities, high-tech industries and the real sector of the economy. The necessity of eliminating the existing contradictions in the tax legislation, improving the system of responsibility of banks in order to minimize offenses from this segment of the economy is revealed. Scope of application of the research results. The results of the study can be used in the process of adopting regulatory legal acts aimed at improving legislation in the field of taxation of the banking sector of the economy. Conclusions. The main conclusion of the study is the justification of the need to form tax tactics and strategies in relation to investor banks, the need for tax support for bank lending to priority sectors of the economy based on the differentiation of income tax rates by type of banking activity and services provided.

Keywords: banking organizations, tax system, income tax, lending, tax liability, transactions, spe-

Введение. Система налогообложения банковских организаций является составной, специфической частью российской системы налогообложения, обусловленной особенностями банковской деятельности и их ролью в воспроизводственных процессах. В любой налоговой системе банки выполняют особую роль (самостоятельного плательщика налогов и агента по перечислению налогов в бюджет). Устойчивость банковской системы влияет на уровень устойчивости всего государства.

Раскрывая роль банковских организаций в налоговой системе Российской Федерации, нельзя не отметить, что они являются одними из значимых инвесторов в реальном секторе экономики страны. При умелом применении налоговые методы регулирования призваны формировать макроэкономические условия, наиболее благоприятные для функционирования банковской системы, что способствует ее устойчивости к конъюнктурным колебаниям, превращению в активный инструмент инвестиционных процессов и экономического роста.

Актуальным вопросам построения эффективной системы и анализа особенностей налогообложения банков посвящены научные труды многих зарубежных и российских ученых. Среди наиболее значимых трудов следует выделить работы таких исследователей, как: Mikes A. [18], Freebairn John [17], Phua Y. S. [19], Вылкова Е. С. [2], Гончаренко Л. И. [3], Кичигина А. К. [5], Ланцова Н. М. [7], Шурина С. В. [19] и др.

Однако, несмотря на проведение учеными ряда значимых исследований, в их работах недостаточное внимание уделяется анализу ключевых проблем механизма налогообложения банковских организаций и нахождению путей их решения на современном этапе Российской Федерации. Хотя система налогообложения банков в России постоянно трансформируется, тем не менее ей присущи недостатки. Отдельные ее элементы являются неэффективными (применение единой ставки налога на прибыль организаций для банковских операций), а в ряде случаев и противоречивыми (в особенности в части отделения облагаемых операций от не облагаемых НДС, целесообразности взимания данного налога с банков). Нельзя не отметить также, что отсутствует в свободном доступе полноценная официальная информация о размерах налоговых платежей, уплаченных кредитными организациями в общей сумме доходов бюджета российского государства, что, в свою очередь, затрудняет анализ состояния банковского сектора [9].

Кроме того, в отечественной практике отсутствует специальный налог, отражающий специфику деятельности банков. При этом они уплачивают аналогичные налоги, что и другие субъекты хозяйствования. К сожалению, действующая система налогообложения банковских организаций не позволяет данному сектору экономики в полной мере реализовать возможный фискальный и регулирующий потенциалы.

Материалы и методы исследования. Основными источниками анализируемых показателей выступили статистические и отчетные данные Федеральной службы государственной статистики [13], ФНС Россиимм [14], УФНС России по Республике Дагестан [12], публичного 
акционерного общества (ПАО) «Сбербанк России» [11]. Для обработки статистических данных использовались методы факторного и сравнительного анализа, обобщения и группировки, выборки и другие статистические методы.

Результаты. Необходимо отметить, что в качестве специфических самостоятельных участников налоговых отношений банковские организации в российском законодательстве прямо не выделены. Тем не менее Налоговый кодекс РФ (в отдельных статьях) устанавливает статус, права и обязанности коммерческих банков, что фактически определяет их важнейшую роль в отечественной налоговой системе.

В соответствии с действующим российским законодательством банковские организации уплачивают общеустановленные налоги. Система налогообложения банков представлена такими налогами, как: НДС, налог на прибыль, налог на имущество организаций, земельный налог, налог на доходы физических лиц (при взимании данного налога с работников банки выполняют функции налогового агента), транспортный налог, госпошлина (при наличии объекта налогообложения). Банковские организации, как и другие субъекты хозяйствования, перечисляют также страховые взносы во внебюджетные социальные фонды. В условиях России страховые взносы во внебюджетные социальные фонды, хотя и увеличивают налоговую нагрузку, но при этом не включаются в систему общего налогообложения.

Специфика финансово-хозяйственной деятельности банковских организаций обусловливает особенности методики налогообложения данной категории налогоплательщиков. В частности, в методических аспектах исчисления и взимания налогов с банковского сектора экономики специфика характерна таким налогам, как налог на прибыль и НДС. Остальные же налоги банковские организации уплачивают в общеустановленном порядке.

Ключевым налогом в системе налогообложения кредитных организаций РФ является налог на прибыль. С 1.01.2002 в соответствии с главой 25 Налогового кодекса в России применяется обновленная методика исчисления и уплаты налога на прибыль организаций [10]. При этом данная методика характеризует общие основы налогообложения всех плательщиков, а также особенности налогообложения отдельных категорий, в том числе банков. В России с принятием и введением в действие главы 25 НК РФ были отменены действующие льготы по налогу на прибыль организаций и установлена единая ставка налога для всех субъектов хозяйствования, включая банки.

Главная особенность доходов банков состоит в том, что основной удельный вес в них принадлежит доходам, которые у остальных плательщиков налога на прибыль относятся к прочим доходам и носят самостоятельный характер для целей налогообложения в составе внереализационных доходов. Для банков же эти доходы связаны непосредственно с реализацией их специфических услуг. В ст. 264 НК РФ в составе прочих расходов выделяются расходы на содержание собственной службы безопасности по выполнению функций защиты банков и сохранности материальных ценностей и т. п.

Другим налогом, уплачиваемым банковскими организациями, является налог на добавленную стоимость. Банковские операции, за исключением операций по инкассации, НДС не облагаются. Освобождается от НДС также оказание финансовых услуг по предоставлению займа в денежной форме. При этом все остальные банковские сделки и услуги подлежат налогообложению по основной $20 \%$ ставке. Следует отметить, что, хотя операции, подлежащие и не подлежащие обложению НДС, прописаны в главе 21 НК РФ, на практике весьма сложно отделить облагаемую операцию от необлагаемой налогом на добавленную стоимость.

Как показал проведенные в работе анализ и оценка методики исчисления и взимания налога на прибыль, в РФ в целом установлена невысокая процентная ставка по данному налогу для банковского сектора экономики. Однако, несмотря на это, следует отметить, что действующий механизм налогообложения банковских организаций в отечественной практике имеет ряд сложностей. Это относится как к проблемам толкования соответствующих глав Налогового кодекса, регулирующих порядок уплаты налога на прибыль организаций и НДС, так и к отсутствию льгот для банков, кредитующих наукоемкие отрасли и реальный сектор экономики. Одной из сложностей при расчете налога на прибыль организаций выступает задача отнесения доходов или расходов к реализации банковских услуг или внереализационным расходам, что прямым образом искажает реальный финансовый результат деятельности банков. Следует так- 
же отметить, что в мировой практике в отношении сверхприбылей кредитных организаций, как правило, применяется прогрессивное налогообложение (с увеличением налогооблагаемой прибыли ставка налога растет). В отечественной практике в отличие от многих зарубежных стран в методике исчисления и взимания налога на прибыль отсутствует прогрессия.

Несмотря на стимулирование банковской системы России относительно невысокой ставкой налога на прибыль, механизм формирования налоговой базы по налогу на прибыль все же не дает возможность развиваться кредитным организациям в полной мере. Система налогообложения банков в условиях модернизации экономики должна быть тем экономическим рычагом, при помощи которого производителю выгодно развивать производство, в особенности в инновационной сфере. Действующие ставки по кредитам значительно удорожают российскую продукцию, существенно снижают ее конкурентоспособность и не оставляют предприятиям достаточных средств для саморазвития.

В российском законодательстве в механизме налогообложения необходимо предусмотреть возможность применения более низкой ставки налога на прибыль для кредитных организаций в том случае, если они систематически направляют прибыль не на выплату дивидендов, а на кредитование инновационной деятельности, наукоемких отраслей и реального сектора экономики. Данный сектор экономики призван решать проблемы импортозамещения в российской практике, поэтому должен иметь преимущества при получении кредитов. Государство может и должно с помощью налогового механизма своевременно решать актуальные проблемы реальной ситуации в экономике РФ на современном этапе.

Вариант дифференциации ставок налога на получаемую прибыль для кредитных организаций в разрезе видов деятельности и получаемой прибыли может быть следующим: кредитование инновационной деятельности и наукоемких отраслей экономики (включая для it- технологии) - $10 \%$; кредитование реального сектора экономики, а также социального предпринимательства $-13 \%$; кредитование прочих операций, не ниже основной ставки, $-20 \%$.

Возможно также проведение экспертных оценок о целесообразности введения повышенной ставки налога на прибыль (до 25-30 \%), для банков по доходам, полученным от спекулятивных операций, операций с финансовыми и валютными транзакциями. Данная мера позволит компенсировать потери бюджета в связи с введением низкой ставки налога по кредитованию инновационной деятельности, наукоемких отраслей и реального сектора экономики. Несмотря на высокую ставку обложения прибыли, от спекулятивных операций банки, вероятнее всего, не откажутся, поскольку они зачастую являются самыми простыми и доходными [7].

Необходимо отметить, что в отдельных странах уже длительное время взимается специальный дополнительный налог с валютных и финансовых транзакций, обладающих высоким уровнем доходности. К примеру, такое обложение имеет место в США, Великобритании, Швеции, в Китае и в ряде других стран.

В свою очередь, кредитным организациям необходимо вести дифференцированную ставку по кредиту с прописанием условий его применения в договоре кредитования. К примеру: если кредит одобрен под $13 \%$ годовых, в случае достижения цели на который он был взят (достижение положительного исхода) ставка кредита может быть снижена до 10 \% годовых. В результате достигается тройной эффект, соблюдение интересов всех участников:

- во-первых, для клиента банка - кредит с низкой ставкой, дающий возможности роста и развития собственного бизнеса;

- во-вторых, для банка - обложение налогом на прибыль собственных доходов по сниженной ставке;

- в-третьих, для государства - рост инвестиций и развитие приоритетных отраслей экономики.

Таким образом, дифференцируя ставку налога на прибыль по видам банковских операций, услуг и сделок, а также усиливая меры контроля и санкции, в случаях преступной и незаконной деятельности банков можно наиболее полно реализовать фискальный и регулирующий потенциалы механизма банковского налогообложения, более успешно решать задачи развития современных приоритетных отраслей и секторов экономики.

В условиях затрудненного доступа к иностранным источникам финансирования для кредитных организаций России формирование ресурсной базы происходит преимущественно за 
счет сбережений населения и вложений корпоративного сектора [16]. Регулирование налоговой составляющей в финансах коммерческих банков должно быть таким, чтобы они функцио-

\begin{tabular}{|c|c|c|c|c|c|}
\hline \multirow[b]{2}{*}{ Показатели } & \multicolumn{3}{|c|}{ Млрд руб. } & \multicolumn{2}{|c|}{ Темпы изменений, в \% } \\
\hline & 2017 & 2018 & 2019 & $\begin{array}{r}2019 \\
/ 2017\end{array}$ & $\begin{array}{l}2019 \\
/ 2018\end{array}$ \\
\hline $\begin{array}{l}\text { Всего налоговых поступлений, в } \\
\text { том числе: }\end{array}$ & 17476,34 & 21328,55 & 22757,12 & 131,7 & 106,6 \\
\hline С банковских организаций & 436,73 & 362,64 & 500,73 & 114,6 & 138,1 \\
\hline Удельный вес, \% & 2,5 & 1,7 & 2,2 & - & - \\
\hline
\end{tabular}

По выше приведенным данным таблицы 1 следует, что, несмотря на общий рост налоговых поступлений в консолидированный бюджет РФ за 2018 год на 22,2 \%, объем уплаченных налогов банковскими организациями составил 362,64 млрд руб., что на $17,0 \%$ ниже аналогичного показателя за 2017 год. Это можно объяснить наблюдаемым в России в анализируемом 2018 году снижением ликвидности банковской системы и значительным сокращением количества региональных банков. Часть региональных банков была закрыта в связи с теневой деятельностью из-за использования в практике незаконных схем отмывания денежных средств. Однако другая часть (в основном малые и средние банки) фактически искусственно «выдавливалась» с финансового рынка. Известно, что при этом в странах с развитой экономикой полноправно функционируют как крупные, так средние и малые банки. Общеизвестна проблема низкой капитализации российских банков и банковской системы в целом. К сожалению, в последние годы Банк России пытается решить ее сугубо административными методами, повышая требования к минимальному размеру собственных средств банков.

Анализ налоговых поступлений в консолидированный бюджет Российской Федерации за 2019 год в сравнении с 2018 годом показывает небольшое увеличение доли налоговых поступлений от финансового сектора в общем объеме налоговых поступлений в бюджет. Так, по данным таблицы 2 , следует, что объем уплаченных кредитными организациями налогов в консолидированный бюджет Российской Федерации в 2019 году составил 500,73 млрд руб., что на 138,1 млрд руб., или 38,1 \%, превысило показатель 2018 года. Основной фактор роста налоговых отчислений - увеличение доходов кредитных организаций, среди прочих факторов можно выделить увеличение операций с государственными ценными бумагами.

Одним из стратегически важнейших субъектов СКФО РФ является Республика Дагестан (РД). Рассмотрим роль банков в формировании отраслевой структуры налоговых платежей по Республике Дагестан в динамике за 2017-2019 годы. Банковская система Республики Дагестан на 01.05.2020 насчитывает 94 кредитно-кассовых учреждений, в том числе 2 собственные кредитные организации, четыре филиала кредитных организаций других регионов (в том числе Дагестанское отделение ПАО «Сбербанк России»), 88 внутренних структурных подразделений кредитных организаций (филиалов). Данные таблицы 2 показывают, что уровень налоговых поступлений с кредитных организаций в Республике Дагестан еще более низок (менее 2 \%), чем в целом по России.

В 2018 году по сравнению с 2017-м в Республике Дагестан связи с уменьшением количества функционирующих кредитных организаций наблюдалось заметное снижение налоговых поступлений с банковского сектора экономики. Так, в период 2017-2018 годов в Дагестане были массово сокращены региональные банки, где основными причинами послужили низкий уровень капитализации региональных банков, а также использование отдельными банками незаконных схем уклонения от уплаты налогов.

В прошедшем 2019 году ситуация относительно стабилизировалась, наблюдался рост прибыли в деятельности большинства банковских организаций, функционирующих в регионе. Это привело к увеличению удельного веса налоговых поступлений с банковского сектора экономики с 1,5 до $1,7 \%$. В целом такой рост налоговых поступлений можно объяснить как ростом полученной прибыли банковскими организациями, так и улучшением налогового администриро- 
MУCAEBA X.M.

СИСТЕМА НАЛОГООБЛОЖЕНИЯ БАНКОВСКИХ ОРГАНИЗАЦИЙ: СОСТОЯНИЕ И ПУТИ ПОВЫШЕНИЯ ЭФФЕКТИВНОСТИ

Таблица 2

Сравнительные данные об общем объеме налоговых поступлений и фискальной

\begin{tabular}{|l|c|c|c|c|c|c|}
\hline \multicolumn{1}{|c|}{ Виды налогов и платежей } & \multicolumn{2}{|c|}{2017} & \multicolumn{2}{|c|}{2018} & \multicolumn{2}{c|}{2019} \\
\hline Всего поступлений, в том числе: & 33278,8 & 100,0 & 39278,8 & 100,0 & 45356,3 & 100,0 \\
\hline с банковских организаций & 700,2 & 2,1 & 589,2 & 1,5 & 771,0 & 1,7 \\
\hline
\end{tabular}

*Рассчитано по: отчетные данные Управления ФНС России по Республике Дагестан за 2017-2019 годы (отчеты № 1-HM, 4нм) [12].

По мнению известного российского ученого Л. И. Гончаренко, «банки, занимая срединное положение между налогоплательщиками и бюджетом, оказывают существенное влияние на исполнение доходной части бюджета» [3]. По мнению другого российского исследователя, банк выполняет роль налогового посредника, обеспечивающего поступление налогов в бюджет [1]. Это подтверждается следующими обстоятельствами: кредитные организации обязаны своевременно и в полном объеме перечислять налоги в бюджеты различных уровней, причем делать это они должны совершенно бесплатно, в противоречие принципам коммерческой деятельности. С одной стороны, Д. А. Васильев рассматривает банк как коммерческую организацию, а с другой - приравнивает к органам Федерального казначейства. О преобладании посреднической роли банков в своих трудах упоминает также известный российский ученый А. 3. Дадашев [4]. Между тем известный канадский ученый Сэнгер Тоби отмечает, что «серьезные изменения в системе налогообложения, введенные за последние десятилетия и вдохновленные экономикой предложения, дали финансовому сектору и отдельным его высокооплачиваемым работникам огромные преимущества. Налоговые льготы, давшие финансовой индустрии несоразмерные преимущества и даже дополнительно стимулировавшие спекулятивное поведение, также должны быть отменены» [15].

Таким образом, российские экономисты делают акцент на роли банков как посредника, отодвигая его как налогоплательщика на второй план, хотя уровень налогообложения кредитных организаций прямо или косвенно влияет на все сферы экономики, способность своевременно перечислять налоги в бюджет. Из-за превалирования узкого подхода к роли банков в экономике неслучаен низкий уровень налоговых поступлений с банковского сектора в российской практике. В целом, как было отмечено выше, доля налоговых поступлений в бюджет от банковского сектора экономики в России чрезмерно низкая по сравнению с другими отраслями.

В Российской Федерации ежегодно для целей налогообложения разрабатывается учетная политика банка с учетом требований налогового законодательства и нормативно-правовых документов по вопросам налогообложения Министерства финансов РФ и ФНС России. Однако следует отметить об имеющихся противоречиях в данных нормативных актах, к примеру в отношении наложения штрафных санкций за нарушения банками требований Центрального банка РФ. Размеры данных штрафных санкций различны в уголовном и налоговом законодательствах, при этом они фактически не существенны для кредитных организаций и не могут быть достаточным стимулом соблюдения ими законодательства. В сложившей ситуации возникает необходимость устранения противоречий в законодательных актах в целях повышения действенности налоговых санкций и упрощения процедур их администрирования. Строгие меры к нарушителям налогового законодательства должны сочетаться с мерами, направленными на максимальное упрощение механизма налогообложения. Когда налоговое законодательство является чрезмерно сложным, возрастает риск неуплаты налогов. В данном контексте следует согласиться с рекомендациями известного специалиста по вопросам налогообложения Ч. Малура, который сразу после распада СССР рекомендовал странам постсоветского пространства строить исключительно простые налоговые системы [8]. Когда налоговое законодательство является чрезмерно сложным, возрастает риск неуплаты налогов.

Выводы и предложения. Как показало проведенное нами исследование, система налогообложения банковских организаций в отечественной практике нуждается в дальнейшем совер- 
шенствовании. В целом комплекс мер по совершенствованию механизма налогообложения банковских организаций в условиях РФ может быть сведен к следующему:

- во-первых, необходима разработка государственной стратегии развития банков - инвесторов в ключевые отрасли экономики, где значимая роль должна отводиться налоговому механизму;

- во-вторых, для достижения обозначенной стратегической цели необходимо в законодательстве предусмотреть дифференцированный механизм налогообложения прибыли банковских организаций в связи со снижением его ставок при кредитовании современных приоритетных отраслей экономики;

- в-третьих, снижение ставок налога на прибыль по кредитованию приоритетных отраслей экономики должно одновременно сопровождаться усилением налогообложения спекулятивных операций и финансовых транзакций, обладающих высоким уровнем доходности, что позволит не допустить уменьшения доходов бюджетной системы российского государства в

Лuтература

1. Васильев Д. А. Роль банков в налоговом администрировании. // Налогообложение, учет и отчетность в коммерческом банке. - 2007. - № 7. - С. 38 .

2. Вылкова Е. С. Налогообложение в Германии: монография / Е. С. Вылкова. - СПб.: Северо-Западный институт повышения квалификации ФНС России, 2013. - С. 207-210.

3. Гончаренко Л. И. Методология налогообложения и налогового администрирования коммерческих банков России //Диссертация на соискание ученой степени доктора экономических наук / Финансовая академия. - Москва, 2009

4. Дадашев А. 3. Налогообложение коммерческих банков в Российской Федераиии. - Ученое пособие. М.: «Книжный мир», 2008. - C. 7-30.

5. Кичигина А. К., Конвисарова Е. В. Сравнительная характеристика налогообложения прибыли коммерческих банков в России и за рубежом // Налоги и налогообложение. - 2016. - № 6. - С. 457-465.

6. Клюкович С. В. Налогообложение коммерческих банков в российской налоговой системе // Тегra Economicus. - 2011. - T.9. - № 1-2. -C. 70-72.

7. Ланцова Н. М., Зырянова О. В. Налоговое планирование платежей по налогу на прибыль в коммерческом банке: практика и перспективы развития // Вестник образовательного консорциума. Среднерусский университет. Серия: Экономика и управление. - 2018. - № 11. - C. 82-85.

8. Маклур Ч. Е. Налоговая политика для России // Мировая экономика и международные отношения. 1993. - № 8. - C. 37.

9. Мусаева Х. М., Джапарова Л. Г. Система налогообложения кредитных организаций и ее эффективность // Финансы и кредит. - 2018. - T. 24. - № 2 (770). - С. 304-314.

10. Налоговый кодекс РФ (НК РФ), 2020. [Электронный ресурс]. Режим доступа: http:// www.nalogovyykodeks.ru/(1.09.2020), свободный. - Загл. с экрана.

11. Отчетные данные ПАО «Сбербанк России» за 2016-2018 годы. [Электронный ресурс]. Режим доcmyna: https://www.vbr.ru/banki/sberbank-rossii/oficialnye-resursy/. (09.10.2020), свободный. - Загл. с экрана.

12. Офиииальные данные Управления Федеральной налоговой службы по Республике Дагестан за 20172019 годы. [Электронный ресурс]. Режим доступа: https://www.nalog.ru/rn05./(13.10.2020), свободный. - Загл. с экрана.

13. Официальные данные Федеральной службы государственной статистики РФ за 2017-2019 годы. [Электронный ресурс]. Режим доступа: https://rosstat.gov.ru/(1.09.2020), свободный. - Загл. с экрана.

14. Статистические налоговые отчетности Федеральной налоговой службы России за 2017-2019 годы. Официальный сайт ФНС России. [Электронный ресурс]. Режим доступа: https://www.nalog.ru (07.10.2020), свободный. - Загл. с экрана.

15. Сэнгер Т. Налогообложение финансов // Глобальная трудовая колонка. 2011. - Выпуск 66, декабрь. [Электронный ресурс]. Режим доступа: http://www.global-labour- university.org/fileadmin/glu_column/ ru_papers/no_66_sanger.ru (05.10.2020), свободный. - Загл. с экрана.

16. Щурина С. В., Воробьева М. А. Прогнозирование финансовых показателей деятельности банков для обеспечения их стабильного развития // Экономика и управление. - 2018. - №1. - С. 70-79.

17. Freebairn John. Opportunities and Challenges for CGE Models in Analysing Taxation // Economic Papers. - 2017/- Том: 37/-Bыпуск: 1. - Стр. 17-29. [Электронный ресурс]. Режим доступа: https:// doi.org/10.1111/1759-3441.12202, свободный. - Загл. с экрана.

18. Mikes A. From counting risk to making risk count: Boundary work in risk management // Accounting, organizations and society. 2011. Vol. 36. No. 4-5. Pp. 226-245.

19. Phua Y. S., Abernethy M. A., Lills A. M. Controls as Exit Barriers in Multuperiod Outsourcing Arrangements // Accounted Review. 2011. Vol. 86. No. 5. P. 1795-1834.

\section{References:}

1. Vasil'ev D. A. Rol' bankov v nalogovom administrirovanii. // Nalogooblozhenie, uchet $i$ otchetnost' v kommercheskom banke. - 2007. - № 7. - S. 38.

2. Vylkova E. S. Nalogooblozhenie v Germanii: monografiya / E. S. Vylkova. - SPb.: Severo-Zapadnyj institut 
povysheniya kvalifikacii FNS Rossii, 2013. - S. 207-210.

3. Goncharenko L. I. Metodologiya nalogooblozheniya i nalogovogo administrirovaniya kommercheskih bankov Rossii //Dissertaciya na soiskanie uchenoj stepeni doktora ekonomicheskih nauk / Finansovaya akademiya. - Moskva, 2009.

4. Dadashev A. Z. Nalogooblozhenie kommercheskih bankov v Rossijskoj Federacii. - Uchenoe posobie. - M.: «Knizhnyj mir», 2008. - S. 7-30.

5. Kichigina A. K., Konvisarova E. V. Sravnitel'naya harakteristika nalogooblozheniya pribyli kommercheskih bankov v Rossii i za rubezhom // Nalogi i nalogooblozhenie. - 2016. - № 6. - S. 457-465.

6. Klyukovich $S$. V. Nalogooblozhenie kommercheskih bankov v rossijskoj nalogovoj sisteme // Terra Economicus. - 2011. - T.9. - № 1-2. -S. 70-72.

7. Lancova N. M., Zyryanova O. V. Nalogovoe planirovanie platezhej po nalogu na pribyl' v kommercheskom banke: praktika i perspektivy razvitiya // Vestnik obrazovatel'nogo konsorciuma. Srednerusskij universitet. Seriya: Ekonomika i upravlenie. - 2018. - № 11. - S. 82-85.

8. Maklur CH. E. Nalogovaya politika dlya Rossii // Mirovaya ekonomika i mezhdunarodnye otnosheniya. 1993. - № 8. - S. 37.

9. Musaeva H. M., Dzhaparova L. G. Sistema nalogooblozheniya kreditnyh organizacij i ee effektivnost' // Finansy i kredit. - 2018. - T. 24. - № 2 (770). - S. 304-314.

10. Nalogovyj kodeks RF (NK RF), 2020. [Elektronnyj resurs]. Rezhim dostupa: http:// www.nalogovyykodeks.ru/ (1.09.2020), svobodnyj. - Zagl. s ekrana.

11. Otchetnye dannye PAO «Sberbank Rossii» za 2016-2018 gody. [Elektronnyj resurs]. Rezhim dostupa: https://www.vbr.ru/banki/sberbank-rossii/oficialnye-resursy/. (09.10.2020), svobodnyj. - Zagl. s ekrana.

12. Oficial'nye dannye Upravleniya Federal'noj nalogovoj sluzhby po Respublike Dagestan za 2017-2019 gody. [Elektronnyj resurs]. Rezhim dostupa: https://www.nalog.ru/rn05./(13.10.2020), svobodnyj. - Zagl. s ekrana.

13. Oficial'nye dannye Federal'noj sluzhby gosudarstvennoj statistiki RF za 2017-2019 gody. [Elektronnyj resurs]. Rezhim dostupa: https://rosstat.gov.ru/ (1.09.2020), svobodnyj. - Zagl. s ekrana.

14. Statisticheskie nalogovye otchetnosti Federal'noj nalogovoj sluzhby Rossii za 2017-2019 gody. Oficial'nyj sajt FNS Rossii. [Elektronnyj resurs]. Rezhim dostupa: https://www.nalog.ru (07.10.2020), svobodnyj. - Zagl. s ekrana.

15. Senger T. Nalogooblozhenie finansov // Global'naya trudovaya kolonka. 2011. - Vypusk 66, dekabr'. [Elektronnyj resurs]. Rezhim dostupa: http://www.global-labour- university.org/fileadmin/glu_column/ ru_papers/no_66_sanger.ru (05.10.2020), svobodnyj. - Zagl. s ekrana.

16. SHCHurina S. V., Vorob'eva M. A. Prognozirovanie finansovyh pokazatelej deyatel'nosti bankov dlya obespecheniya ih stabil'nogo razvitiya // Ekonomika i upravlenie. - 2018. - №1. - S. 70-79.

17. Freebairn John. Opportunities and Challenges for CGE Models in Analysing Taxation // Economic Papers. - 2017/ - Tom: 37/ - Vypusk: 1. - Str. 17-29. [Elektronnyj resurs]. Rezhim dostupa: https:// doi.org/10.1111/1759-3441.12202, svobodnyj. - Zagl. s ekrana.

18. Mikes A. From counting risk to making risk count: Boundary work in risk management // Accounting, organizations and society. 2011. Vol. 36. No. 4-5. Pp. 226-245.

19. Phua Y. S., Abernethy M. A., Lills A. M. Controls as Exit Barriers in Multuperiod Outsourcing Arrangements // Accounted Review. 2011. Vol. 86. No. 5. P. 1795-1834. 